\title{
Predicting therapeutic response to oral ketamine for chronic suicidal ideation: a Bayesian network for clinical decision support
}

Denise Beaudequin * D, Adem T. Can, Megan Dutton, Monique Jones, Cyrana Gallay, Paul Schwenn, Cian Yang, Grace Forsyth, Gabrielle Simcock, Daniel F. Hermens and Jim Lagopoulos

\begin{abstract}
Background: The glutamatergic modulator ketamine has been shown to result in rapid reductions in both suicidal ideation (SI) and depressive symptoms in clinical trials. There is a practical need for identification of pre-treatment predictors of ketamine response. Previous studies indicate links between treatment response and body mass index (BMI), depression symptoms and previous suicide attempts. Our aim was to explore the use of clinical and demographic factors to predict response to serial doses of oral ketamine for chronic suicidal ideation.

Methods: Thirty-two participants completed the Oral Ketamine Trial on Suicidality (OKTOS). Data for the current study were drawn from pre-treatment and follow-up time-points of OKTOS. Only clinical and sociodemographic variables were included in this analysis. Data were used to create a proof of concept Bayesian network (BN) model of variables predicting prolonged response to oral ketamine, as defined by the Beck Scale for Suicide Ideation (BSS).

Results: The network of potential predictors of response was evaluated using receiver operating characteristic (ROC) curve analyses. A combination of nine demographic and clinical variables predicted prolonged ketamine response, with strong contributions from BMI, Social and Occupational Functioning Assessment Scale (SOFAS), Montgomery-Asberg Depression Rating Scale (MADRS), number of suicide attempts, employment status and age. We evaluated and optimised the proposed network to increase the area under the ROC curve (AUC). The performance evaluation demonstrated that the BN predicted prolonged ketamine response with $97 \%$ accuracy, and $\mathrm{AUC}=0.87$.

Conclusions: At present, validated tools to facilitate risk assessment are infrequently used in psychiatric practice. Pre-treatment assessment of individuals' likelihood of response to oral ketamine for chronic suicidal ideation could be beneficial in making more informed decisions about likelihood of success for this treatment course. Clinical trials registration number ACTRN12618001412224, retrospectively registered 23/8/2018.
\end{abstract}

Keywords: Ketamine, Suicidal ideation, Bayesian network, Complex system, Response, Predictive modelling, Clinical trial

\footnotetext{
* Correspondence: dbeaudeq@usc.edu.au

Thompson Institute, University of the Sunshine Coast, Locked Bag 4 (ML59),

Maroochydore DC, QLD 4558, Australia
}

(c) The Author(s). 2020 Open Access This article is licensed under a Creative Commons Attribution 4.0 International License, which permits use, sharing, adaptation, distribution and reproduction in any medium or format, as long as you give appropriate credit to the original author(s) and the source, provide a link to the Creative Commons licence, and indicate if changes were made. The images or other third party material in this article are included in the article's Creative Commons. licence, unless indicated otherwise in a credit line to the material. If material is not included in the article's Creative Commons licence and your intended use is not permitted by statutory regulation or exceeds the permitted use, you will need to obtain permission directly from the copyright holder. To view a copy of this licence, visit http://creativecommons.org/licenses/by/4.0/ The Creative Commons Public Domain Dedication waiver (http://creativecommons.org/publicdomain/zero/1.0/) applies to the data made available in this article, unless otherwise stated in a credit line to the data. 


\section{Background}

Suicide remains a leading and preventable cause of death globally [1]. In Australia, it is estimated that 3046 people died from intentional self-harm in 2018 [2]. Yet, to date, there is no definitive pharmacological treatment for individuals with chronic suicidal ideation (SI). SI is defined as "thoughts about self-harm, with deliberate consideration or planning of possible techniques of causing one's own death" [3]. Current biological approaches to treating SI include antidepressants [4], lithium [5], clozapine [6], and electroconvulsive therapy [7]. However, these treatments have limitations. For instance, despite the range of pharmacological options, approximately half of patients remain treatment resistant even after months of use and continue to experience ongoing SI [8]. Further, selective serotonin reuptake inhibitors and serotonin and norepinephrine reuptake inhibitors, usually first-line antidepressant treatments, require 3-8 weeks to improve mood [8, 9], leaving individuals at greater risk for SI [10]. This highlights the need for new approaches.

\section{Ketamine treatment in suicidal ideation}

The N-methyl-D-aspartate receptor antagonist ketamine, a widely used general anaesthetic and short-acting analgesic agent, has increasingly been used to treat chronic suicidal ideation. Ketamine treatment has been shown to result in rapid reductions in both SI and depressive symptoms in several clinical trials [11-13]. However, while ketamine is considered a promising treatment for patients with treatmentresistant depression and SI, individual patients vary in their response to ketamine $[14,15]$, and some individuals do not respond sufficiently, even with serial, titrated treatments. The reasons for the heterogeneity of response to ketamine are unclear but may reflect differences in individuals' underlying demographic attributes, pathophysiology, genetic makeup, and clinical features [10]. The ability to systematically estimate the likelihood of a positive response to ketamine on an individual basis would be beneficial to clinicians and researchers. Identification of pre-treatment predictors of response, such as clinical, phenotypic and biological variables, will provide significantly improved clinical outcomes for patients and represent an opportunity for personalised healthcare provision [10]. Prediction analyses have the potential to provide insights into treatment candidacy and personalised treatment selection for suicidal individuals.

The objective of this study was to develop a simple, practical method of predicting the likelihood of sustained therapeutic response to serial doses of oral ketamine for chronic SI.

Using Bayesian network (BN) methodology, we combined demographic variables with pre-treatment clinical symptoms measured by clinical rating scales, to evaluate their potential to predict sustained response following the treatment course. We hypothesised that these factors, considered in unison, were eligible predictors of treatment response, defined as reduction in SI following a course of ketamine treatment in patients with chronic SI. The ensuing model forms the basis of a decision support system to augment clinical decision making.

\section{Predictors of response to ketamine}

While numerous studies have aimed to identify predictors of ketamine's treatment effect in treatment-resistant depression [10, 16-19], there appear to be fewer studies investigating predictors of ketamine response in chronic SI. Predictors such as positive family history of alcohol dependence [16], higher body mass index (BMI) $[17,18]$, pre-treatment anxious depression [20] and lower ratio of slow wave sleep activity [21] have been found to correlate with greater antidepressant response to a single dose of ketamine. In their study of clinical predictors of ketamine response in treatment resistant depression, Niciu, Luckenbaugh [17], found significant correlations between change-from-baseline Hamilton Depression Rating Scale and higher BMI, family history of alcohol use disorder and prior history of suicide attempt(s). Rong, Park [10] undertook a narrative review to identify multiple pre-treatment predictors of response to ketamine in treatment-resistant depression. Predictors included clinical variables (BMI, history of suicide attempts, family history of alcohol use disorder), neurochemical variables (glutamine/ glutamate ratio), neuroimaging variables (anterior cingulate cortex activity), and indicators of cognitive functioning (processing speed). High BMI and a positive family history of alcohol use disorder were the most replicated predictors of treatment outcomes in this review. Del Sant, Magalhães [19] conducted a literature review to explore clinical characteristics predicting response to ketamine. In this study the sociodemographic variables of positive family history of alcohol abuse disorder in a first-degree relative, higher BMI and negative history of suicide attempts were associated with improvements in depression scores post- ketamine infusion. Ballard, Yarrington [15] developed data-driven groups of SI trajectories after ketamine administration, pooled from five clinical ketamine trials. This study evaluated clinical, demographic and neurobiological factors that might predict SI response to ketamine and found that a longstanding history of chronic SI and self- injury were associated with nonresponse to ketamine. These results emphasised the heterogeneity of SI response to ketamine and the potential independence of SI response from changes in depressed mood.

\section{Novel statistical methods for inference and prediction}

Datasets used in psychiatric research now typically contain thousands of variables from multiple sources. Advances in neuroimaging, electroencephalograms and other multimodal sensing technologies have provided researchers with unprecedented capabilities for characterising subsyndromal and pathologic processes - and 
responses to interventions - in psychiatry, neuroscience and psychology $[22,23]$. Such technologies provide volumes of data that exceed the capacity of classical statistical inference methods. Novel statistical methods are required to weigh the predictive power of multiple variables, especially clinical and demographic characteristics, in studies with limited samples [17]. Machine and statistical learning are being proposed as solutions to the ' $21^{\text {st }}$ century psychiatry's information overload problems' [23].

\section{Bayesian networks (BN)}

$\mathrm{BN}$ are an analytic methodology at the interface of artificial intelligence and statistics and are increasingly being recognised as a useful tool for diagnosis and prediction in complex systems such as health domains [24]. Based on probability distributions, BN are powerful risk assessment tools, particularly valuable for reasoning under uncertainty $[25,26]$, as they provide a transparent evidence base for visualising risk pathways and predicting outcomes. Importantly, Bayesian methods are able to produce reasonable results even with small to moderate sample sizes, especially when strong, defensible prior information is available [27, 28].

A $\mathrm{BN}$ is a directed acyclic graph in which the variables, represented as nodes, are connected by a directed arc implying causality $[25,26,29]$. Chance nodes have a number of user-defined 'states' that can be qualitative or discrete (e.g., 'True/False', 'High/Low', '>5/ 5 5). Conditional probabilities are assigned to each state, and algorithms compute the joint probability distribution of the network. Once quantified, BN can simulate multiple risk pathways, and intervention or exposure scenarios, providing the conditional probability of target outcomes. This particularly appealing feature of $\mathrm{BN}$ to simulate a range of scenarios is achieved by varying the evidence entered into the network. Thus, BN can be used to compare relative risks and examine concomitant interactions between variables, uncover relationships that may not have been apparent, compute the strength of associations between variables, and identify sensitivities for target nodes. The $\mathrm{BN}$ instantly updates when new information is provided and presents outcomes and influences in a straightforward manner to users from any discipline, via a convenient visual platform.

BN offer a systems approach to modelling risk and supporting decision making in complex domains such as psychiatry and medicine $[25,29]$. This boasts several advantages over regression-based methods, in addition to easy transformation into decision support models. Arora et al. (2019) describe BN as knowledge engineering and machine-learning tools for individual-level risk estimation in health science, or 'precision medicine'. For example, Bilek and Karaman [30] used BN modelling to investigate the relationships among psychiatric, demographic and socioeconomic variables and psychometric scales such as the Beck Depression Inventory. In a clinical trial, Cleophas and Zwinderman [31] compared traditional statistical methods (unpaired t-tests, simple and multiple linear regressions) and machine learning (BN methods) in evaluating the efficacy of pravastatin on the decrease of lowdensity lipoprotein cholesterol, concluding that the machine learning methods provided better sensitivity of testing and were more informative. They found that $\mathrm{BN}$ were very efficient in describing multivariate distributions, in addition to being robust with respect to overfitting. BN have been used with different aims in neuroscience, including discovering associations between variables, performance of probabilistic reasoning over the model, and classification of new observations, with and without supervision [32]. In the current study, we propose a BN to predict the likelihood of therapeutic response to serial, weekly oral ketamine treatments in reducing chronic SI. This proof-of-concept model, with further development and validation, has the potential to form the basis of a clinical decision support system, with the aim of more efficient identification of treatment candidacy.

\section{Method \\ Study design and setting}

This study used data collected from the Oral Ketamine Trial on Suicidality (OKTOS; ACTRN12618001412224) exploring the use of oral ketamine for participants with chronic SI conducted at a single centre between August 2018 and October 2019. Although acute SI refers to an acute, immediate or imminent risk requiring urgent psychiatric intervention, chronic SI was defined as experiencing suicidal ideation of varying intensity on a continuous or intermittent basis over a period of months to years, with the ongoing likelihood of a person considering a future attempt.

Participants with chronic suicidal thoughts were referred to OKTOS by their general practitioner or psychiatrist. All participants referred to the trial had a diagnosis of major depressive disorder with one or more comorbidities, including generalised anxiety disorder, bipolar disorder, post-traumatic stress disorder and obsessive-compulsive disorder. The principal investigator and consultant psychiatrist (AC) obtained a psychiatric history and assessed the mental state of participants, including severity and chronicity of their SI.

Participants referred to the trial were offered ketamine under the rationale of having exhausted alternate treatment options for chronic SI or having unsatisfactory treatment outcomes, including being unable to tolerate side effects of currently available treatment; all had failed to respond to at least two pharmacological interventions. Informed, written consent was obtained from individual participants. The trial was approved by the Bellberry $\mathrm{Hu}-$ man Research Ethics Committee (\# 2017-12-982) and approval ratified by the University of the Sunshine Coast Human Research Ethics Committee (\# A181101). The 10-week trial period comprised a pre-treatment 
assessment, followed by a six-week ketamine treatment phase, and a four-week post-treatment follow-up phase.

\section{Inclusion and exclusion criteria}

Participants aged 18 years or over with chronic suicidal thoughts as the primary presenting complaint, determined by the Beck Scale for Suicide Ideation (BSS) score $\geq 6$ at screening, were included in the OKTOS trial. Participants were excluded from the trial if they were experiencing acute SI or had a history of psychosis, mania or hypomania. Full inclusion and exclusion criteria for OKTOS are shown in Table 1. The exclusion criteria developed for the OKTOS trial were derived from ketamine's known, important side effects and align with previous ketamine studies. It is widely recognized that ketamine can cause psychotic, manic and hypomanic symptoms which are acute psychiatric conditions and by themselves can foster a risk of SI [33]. Ketamine can also potentially cause hepatotoxicity, with modest, temporary elevations in liver enzymes noted at anaesthetic doses [34]. Trials investigating the efficacy of sub-anaesthetic doses of IV ketamine for depression consistently report transient elevations in blood pressure and heart rate during the period of the infusion and for up to $80 \mathrm{~min}$ after dosing $[35,36]$.

Participants underwent baseline assessment comprising physical examination, urinalysis, laboratory blood testing, and medical history, obtained by the principal investigator/consultant psychiatrist within 14 days prior to commencement of ketamine treatment. Baseline assessment also included administration of standardised clinical rating scales. During the treatment and followup phase, patients maintained their regular medication regimen as prescribed by their health professionals. Concurrent psychopharmacological agents taken by patients included antidepressants and mood stabilisers.

\section{Treatment}

Participants received sub-anaesthetic doses of oral ketamine during the six-week treatment phase, at one dose per week. The initial dose of ketamine was $0.5 \mathrm{mg} / \mathrm{kg}$, administered in fruit juice by the consultant psychiatrist. Dose amounts were flexible, titrated up by $0.2-0.5 \mathrm{mg} /$ $\mathrm{kg}$ or down by $0.2-0.7 \mathrm{mg} / \mathrm{kg}$ at each treatment, depending on participant tolerance, with a maximum dose of $3.0 \mathrm{mg} / \mathrm{kg}$ at the sixth treatment. Participant tolerance to ketamine was determined by the presence or absence of side effects or discomfort, as measured by tolerability and safety rating scales, vital signs (blood pressure, pulse rate, oxygen saturation, temperature) and urinalysis. $\mathrm{Pa}-$ tients were supervised by mental health nurses (MD, MJ) immediately post treatment and all were seen by the consultant psychiatrist before leaving the study premises. During the trial, patients were assessed via nine study visits and via eleven phone assessments between visits. Study visits occurred at 'baseline', once per week during treatment weeks 1-6 and then at two additional visits during the four-week follow-up phase. Phone assessments, undertaken by mental health nurses primarily to check for adverse effects, took place twice a week after treatments 1-5 and once after treatment 6 .

Vital signs (heart rate, blood pressure, oxygen saturation level and temperature) were recorded at the baseline assessment, as well as three times at the treatment visit - prior to

Table 1 Inclusion and exclusion criteria for the Oral Ketamine Trial on Suicidality (OKTOS)

\begin{tabular}{|c|c|}
\hline Inclusion criteria & Exclusion criteria \\
\hline - Persons aged $\geq 18$ years & $\begin{array}{l}\text { - Psychiatric conditions: } \\
\text { oPsychosis } \\
\text { oMania/hypomania } \\
\text { oAcute suicidal ideation requiring urgent psychiatric intervention }\end{array}$ \\
\hline \multirow[t]{4}{*}{$\begin{array}{l}\text { - Participants with chronic suicidal thoughts as the primary presenting } \\
\text { complaint, determined by Beck Scale for Suicide Ideation - } 21 \text { items } \\
\text { (BSS) score } \geq 6 \text { at screening }\end{array}$} & $\begin{array}{l}\text { - Physical conditions: } \\
\text { o Uncontrolled/severe symptomatic cardiovascular disease states } \\
\text { including recent myocardial infarction (within prior } 6 \text { months); history of } \\
\text { stroke; and hypertension (resting blood pressure > 150/100) } \\
\text { oHistory of intracranial mass, intracranial haemorrhage/stroke, cerebral } \\
\text { trauma/traumatic brain injury or increased intracranial pressure (as } \\
\text { assessed by referring general practitioner) } \\
\text { o liver function test results out of normal range, as specified: } \\
\text {-alanine aminotransferase: }>135 \mathrm{U} / \mathrm{L} \\
\text {-aspartate aminotransferase: }>123 \mathrm{U} / \mathrm{L} \\
\text {-gamma glutamyl transferase male participants: }>210 \mathrm{U} / \mathrm{L} \\
\text {-gamma glutamyl transferase female participants: }>135 \mathrm{U} / \mathrm{L} \\
\text {-total bilirubin }>60 \text { umol/L } \\
\text {-albumin: }<25 \mathrm{~g} / \mathrm{L} \text { and }>150 \mathrm{~g} / \mathrm{L} \\
\text {-alkaline phosphatase: }>345 \mathrm{U} / \mathrm{L}\end{array}$ \\
\hline & $\begin{array}{l}\text { - Previous reaction to ketamine (as reported by referring general } \\
\text { practitioner and participant) }\end{array}$ \\
\hline & - Pregnant women \\
\hline & - Breastfeeding women \\
\hline
\end{tabular}


ketamine administration and at 30- and 60-min posttreatment. Blood samples were taken at four timepoints: at baseline, at the third weekly treatment, just after the last treatment and at the end of the four-week follow-up phase. Serum hematological and biochemical parameters monitored included cholesterol, morning cortisol, brain-derived neurotropic factor, thyroid function, full blood count, liver function, urea and electrolytes. Urinalysis was performed at the pre-ketamine visit as well as prior to all treatments to screen for possible cystitis. Urine pregnancy screening was undertaken for females of childbearing age. Figure 1 illustrates the phases of the trial, including the timing of assessments relevant to the BN study.

\section{Prolonged treatment response}

A prolonged therapeutic response to ketamine treatment was defined as a reduction in SI following a course of six treatments, defined by either (i) $\geqslant 50 \%$ improvement in the pre-treatment BSS score at the end of the four-week post-treatment follow-up phase, or (ii) BSS score $\leq 6$ at the end of the four-week posttreatment follow-up phase [37].

\section{Data collection and preparation}

The clinical rating scales and demographic questions were administered to participants on a touch screen tablet, using the Qualtrics survey platform (Copyright $\odot 2019$ Qualtrics, Provo, UT, USA). The SPSS version 24.0 (IBM Corp 2016) was used for data preparation in conjunction with the Python programming package SciPy [38].

\section{Variables used in the BN}

Variables from OKTOS used in the current study are summarised in Table 2. OKTOS variables were selected as inputs to the prolonged response prediction $\mathrm{BN}$ based on clinical experience or prior evidence in the literature of an association with ketamine response. One latent, discrete variable (profile) was incorporated in the model to prevent formation of very large conditional probability tables. In addition to the demographic variables presented in Table 2, three clinical rating scales included in the final BN structure are described here.

The Social and Occupational Functioning Assessment Scale (SOFAS), used to rate functioning for the current period, focuses exclusively on the individual's level of social and occupational functioning and is not directly influenced by overall severity of the individual's psychological symptoms [39]. The SOFAS is a one-item rating of functioning with a possible range of $0-100$, where higher scores indicate higher social and occupational functioning. The SOFAS is considered to have superior predictive and concurrent validity in comparison to other commonly used measures [40] and has been regularly utilised in clinical populations, including those exhibiting suicidal ideation [41].

The Beck Scale for Suicide Ideation (BSS), a wellestablished clinician rating scale, is a 19-item clinical research instrument designed to assess and quantify the intensity, pervasiveness and characteristics of suicidal ideation in adults [42]. The BSS possible range is $0-38$, with scores of $\geq 6$ indicating clinically significant suicidal ideation. The BSS has been validated in male adults aged 19-75 years $(N=342)$, demonstrating strong correlation between suicide risk assessment and number of previous suicide attempts, with higher BSS scores relating to increased number of suicide attempts [43].

The Montgomery-Asberg Depression Rating Scale (MADRS), is a ten-item diagnostic questionnaire used by psychiatrists to measure the severity of patients' depressive episodes [44]. The MADRS questionnaire includes questions on the following symptoms: apparent sadness, reported sadness, inner tension, reduced sleep, reduced appetite, concentration difficulties, lassitude,

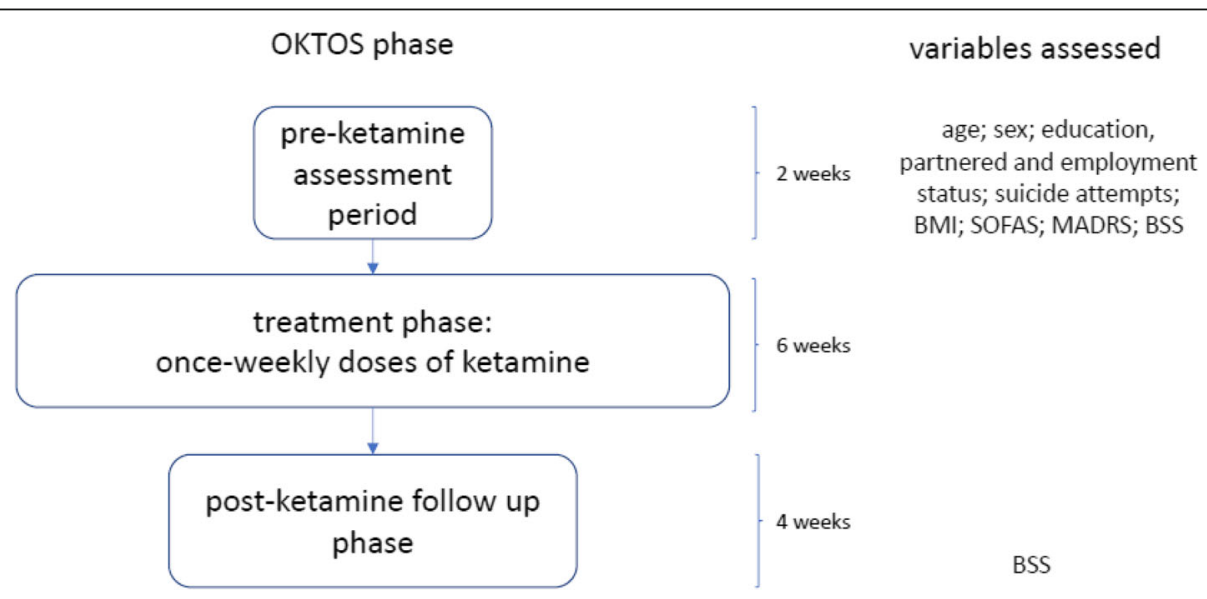

Fig. 1 OKTOS treatment and assessment procedure. BMI = Body Mass Index; SOFAS = Social and Occupational Functioning Assessment Scale; MADRS = Montgomery-Asberg Depression Rating Scale; BSS = Beck Scale for Suicide Ideation 
Table 2 Oral Ketamine Trial on Suicidality (OKTOS) variables used in BN for predicting therapeutic response to ketamine

\begin{tabular}{ll}
\hline OKTOS variable/s & BN node \\
\hline Participant age & Age \\
Sex & Sex \\
Highest education level achieved & Tertiary education \\
Employment status & Employed \\
Marital status & Partnered \\
Number of previous suicide attempts & Suicide attempts \\
Weight in kg/(height in $\mathrm{m}^{2}$ (pre-treatment) & BMI \\
n/a & Profile \\
MADRS (pre-treatment) & MADRS \\
SOFAS (pre-treatment) & SOFAS \\
BSS (end of follow-up phase) & Response \\
\hline
\end{tabular}

inability to feel, pessimistic thoughts, and suicidal thoughts. The possible range for MADRS scores is $0-60$. The MADRS was validated for use in adults in a landmark study by Montgomery and Asberg and has demonstrated excellent inter-rater reliability. This study has been widely cited nationally and internationally [45].

\section{Model structure and parameterisation}

An unparameterised causal network containing 11 variables was created by the OKTOS project team using GeNIe 2.3.3828.0 (๔ BayesFusion LLC, 2019). Demographic variables and pre-treatment clinical rating scales were used as inputs to the model. Input or predictor variables were observed in the pre-treatment phase of the trial and the outcome variable prolonged response was observed at the end of the four-week post-treatment follow-up phase of the trial. Binary states were chosen for all variables except age, suicide attempts and $B M I$, where finer granularity was considered important. Continuous variables were discretised using cutoffs from the literature, or uniform widths where no established cut-offs were available; categorical variables were discretised using cut-offs from the literature or thresholds determined by the study authors where established cutoffs were not available (Table 7 in Appendix). Parameter learning from the discretised data set was accomplished using the expectation-maximisation algorithm [46, 47], with randomised parameter initialisation. Once parameterised, model performance was reviewed and modified by mental health clinicians, in conjunction with the OKTOS project team, then validated by domain experts from the disciplines of psychiatry and neurobiology.

\section{Model validation}

Evaluation of the model was performed using K-fold cross validation [48]. The confusion matrix generated in GeNIe assessed model accuracy as $97 \%$, and the area under the receiver operating characteristic (ROC) curve (AUC) value was found to be 0.87 ; the model correctly predicted $15 / 15$ responders and 14/15 nonresponders. Sensitivity analysis, described in the Results, completed the model validation procedures, in the absence of other Bayesian networks in this domain with which to compare model output.

\section{Scenarios - single or multiple variable evidence introduction}

The parameterised $\mathrm{BN}$ was used to model the effects of single variable or multivariate 'what-if' scenarios. Evidence was introduced in a single variable by selecting a node state. Multivariate scenarios were modelled to demonstrate how the $\mathrm{BN}$ might be used to assist clinical decision making, using four fictional candidates for ketamine treatment for chronic SI. Single variable and multivariate scenarios are presented in the Results.

\section{Statistical analysis}

Categorical variables were described in terms of frequencies and percentages. Continuous variables were summarised as means \pm standard deviation (SD) after assessing for normality using the Shapiro-Wilk test. To study the effect of new evidence introduced into the network on the chosen outcome measures, the percent change $\left(\Delta_{\%}\right)$ in each response node state was calculated as

$$
\Delta_{\%}=\frac{P_{\text {evidence }-} P_{\text {baseline }}}{P_{\text {baseline }}} \times 100 \%
$$

where $P_{\text {baseline }}$ is the probability of occurrence of response node states under baseline network conditions before new evidence is introduced and $P_{\text {evidence }}$ is the probability of a state occurring after new evidence is introduced into the network.

\section{Results}

General characteristics of the study population

Of the 64 participants screened, 40 participants (63\%) met the inclusion criteria for OKTOS. Of these, five were withdrawn due to clinical concerns and three elected not to continue with treatment. A total of 32 participants completed 6 weeks of ketamine treatment, although of these, two participants were not available for follow-up assessment four-weeks after treatment cessation. Participants had a mean (SD) age of 45.7 (14.2) years ( $\min 22.2$ years, max 71.8 years) and mean (SD) weight at first treatment of $91.1 \mathrm{~kg}(24.8) \mathrm{kg}$ (min $56 \mathrm{~kg}$, max $154 \mathrm{~kg}$ ). Twenty-seven participants (84\%) had a medical comorbidity. All participants met Diagnostic and Statistical Manual of Mental Disorders (Fifth Edition; 3) criteria for major depressive disorder and were experiencing chronic SI without psychotic features at the time of commencing the trial. Summary data used in the current study are summarised in Table 3 . 


\section{Treatment outcomes}

At follow-up, 15 of 30 participants (50\%) were assessed as being responders (defined as $\geq 50 \%$ improvement from pretreatment BSS, or BSS $\leq 6$ at the end of the four-week postketamine follow-up phase. Two participants were lost to follow-up. Of the two criteria used to delineate responders, 15 participants $(50 \%)$ showed $\geqslant 50 \%$ improvement in the pretreatment BSS score, and 12 participants $(40 \%)$ had BSS scores $\leq 6$ at the end of the follow-up period (Table 4). Ten participants (33\%) were assessed as being in full remission (defined as BSS $=0$ ) at the end of the 10-week trial period.

\section{Baseline network and sensitivity assessment}

The parameterised $\mathrm{BN}$ at baseline (i.e., with no evidence introduced) is shown in Fig. 2.

Sensitivity analysis of model priors was conducted using an algorithm proposed by Kjaerulff and van der Gaag [49] to give an indication of the relative importance of model inputs in terms of precision. The assessment showed that, in a network with no introduced evidence, the target node prolonged response was most sensitive to $B M I$, followed by the SOFAS, $M A D R S$, suicide attempts, employed, age and tertiary education nodes. Table 5 shows the sensitivity of the prolonged response node to all input variables, in rank order of variables with most impact on prolonged response.

In the next section we present four fictional candidates for ketamine treatment for chronic SI, modelling their presenting characteristics as scenarios in the $\mathrm{BN}$.

\section{Scenarios}

\section{Scenario 1 'Tiffany'}

Tiffany, aged 23, has not been able to find a job since finishing her university degree. Tiffany's BMI indicates she is overweight, and she has attempted suicide once. Her SOFAS is low and her MADRS score indicates her depression is in the moderate range. The $\mathrm{BN}$ model indicates that the chance of Tiffany having a prolonged response to oral ketamine is $50 \%$ (Fig. 3).

\section{Scenario 2 'Brianna'}

Brianna, aged 45, has a long history of depression and chronic SI and has attempted suicide several times. Brianna's MADRS indicates her depression is severe. She is very fit as she exercises regularly, and her BMI is in the healthy range. Brianna is working part time as a casual and reports good relationships with her co-workers and family - her SOFAS is high. The model indicates that the chance of Brianna having a prolonged response to ketamine is 95\% Fig. 4.

\section{Scenario 3 'Levi'}

Levi, aged 19, left school at 14 . He has recently moved towns to live with his grandmother. He works on a casual basis at a fast food outlet and is overweight. His relocation has exacerbated his depression and his MADRS indicates severe
Table 3 Summary data from Oral Ketamine Trial on Suicidality (OKTOS) used in BN for predicting therapeutic response to oral ketamine ( $n=32$ at pre-treatment assessment phase)

\begin{tabular}{|c|c|c|}
\hline Variable & $n$ & $\%$ \\
\hline \multicolumn{3}{|l|}{ Age } \\
\hline$<25$ years & 2 & 6 \\
\hline $25-44$ years & 13 & 41 \\
\hline $45-64$ years & 15 & 47 \\
\hline$\geq 65$ years & 2 & 6 \\
\hline Female & 16 & 50 \\
\hline Tertiary education & 19 & 59 \\
\hline Employed & 10 & 31 \\
\hline Partnered & 13 & 41 \\
\hline \multicolumn{3}{|l|}{ Suicide attempts } \\
\hline none & 7 & 22 \\
\hline one & 9 & 28 \\
\hline two or more & 16 & 50 \\
\hline \multicolumn{3}{|l|}{ BMI } \\
\hline healthy & 11 & 34 \\
\hline overweight & 7 & 22 \\
\hline obese & 14 & 44 \\
\hline \multicolumn{3}{|l|}{ MADRS } \\
\hline not severe & 4 & 13 \\
\hline severe & 28 & 87 \\
\hline \multicolumn{3}{|l|}{ SOFAS } \\
\hline low & 11 & 34 \\
\hline high & 21 & 66 \\
\hline \multicolumn{3}{|l|}{ Prolonged response } \\
\hline yes & 15 & $50^{\circ}$ \\
\hline no & 15 & $50^{\circ}$ \\
\hline
\end{tabular}

depression and his SOFAS is low. He has a history of several suicide attempts. The model suggests that Levi's chance of prolonged response to ketamine treatment is $1 \%$ (Fig. 5).

\section{Scenario 4 'Kamal'}

Kamal, aged 39, married, is from a non-English speaking background and has a tertiary education. Kamal has been unable to find a job using his qualifications since coming to

Table 4 Concurrence of two study response criteria $(n=30)$

\begin{tabular}{llll}
\hline & & Criterion 2 & \\
& & yes & no \\
Criterion 1 & yes & $12(40 \%)$ & $3(10 \%)$ \\
& no & $0(0 \%)$ & $15(50 \%)$
\end{tabular}

Criterion $1=\geq 50 \%$ improvement from pre-treatment BSS at end of 4-week post-ketamine follow-up phase

Criterion $2=$ BSS $\leq 6$ at end of 4-week post-ketamine follow-up phase; 2 participants lost to follow-up 


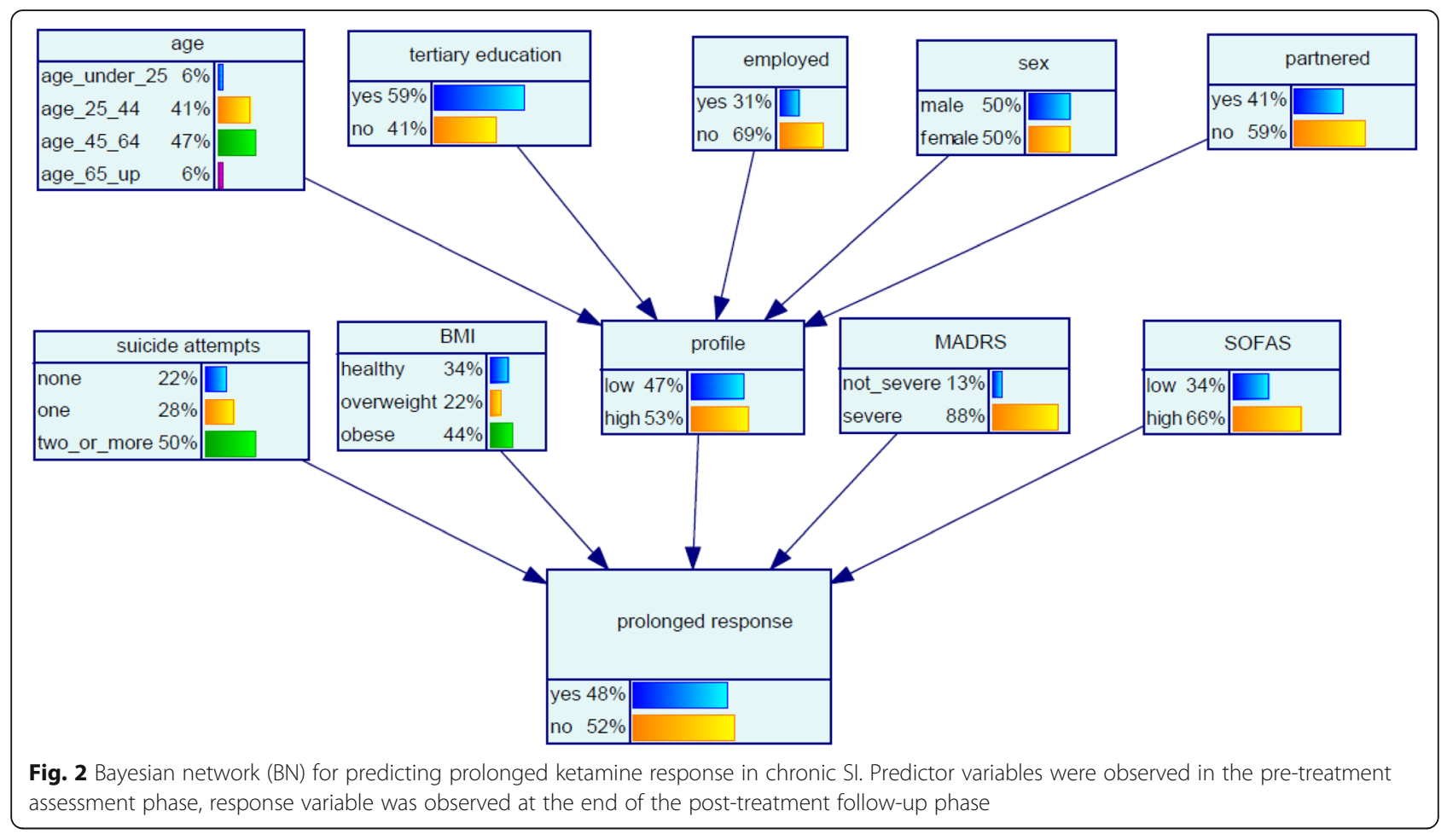

Australia. He has been referred with a history of chronic SI and has attempted suicide once. Kamal's MADRS indicates his depression is severe, and his SOFAS score is 57. Kamal's BMI is in the healthy category. The model suggests that the likelihood of Kamal having a prolonged response to oral ketamine is $98 \%$ (Fig. 6).

\section{Evidence entered in single nodes}

In addition to the multivariate scenarios, we examined the effect of evidence entered in single predictor nodes on the outcome variable prolonged response (Table 6). Participants were more likely to have a prolonged

Table 5 Prior (no new evidence) sensitivity of prolonged response node to input nodes in order of decreasing sensitivity of the prolonged response node to inputs. Table shows maximum sensitivity analysis derivatives [49]

\begin{tabular}{ll}
\hline Input node to prolonged response & $\begin{array}{l}\text { Maximum sensitivity } \\
\text { analysis derivative }^{\text {a }}\end{array}$ \\
\hline BMI & 0.182 \\
SOFAS & 0.171 \\
MADRS & 0.116 \\
Suicide attempts & 0.105 \\
Employed & 0.067 \\
Age & 0.043 \\
Tertiary education & 0.024 \\
Sex & 0.014 \\
Partnered & 0.008
\end{tabular}

${ }^{\mathrm{a} K j a e r u l f f}$ and van der Gaag [49] response to ketamine if they were male, aged under 25 years, had no tertiary education, were not partnered, had no previous suicide attempts and had a healthy BMI. Participants were also more likely to respond if they had a 'high' SOFAS (i.e. > 55) or a MADRS score in the range 0 to 34 (i.e. not severe) at their pre-treatment assessment. Significantly, whether evidence entered in a single node increased or decreased the likelihood of a positive therapeutic response varied according to the combinations of evidence in other nodes. For example, although not having a tertiary education increased the chance of prolonged response by $4 \%$ in this sample (Table 6), when combined with evidence described in Scenario 2, not having a tertiary education decreased Brianna's chance of a prolonged response to ketamine from 95 to $91 \%$ (a decrease of $4 \%$ ).

\section{Discussion}

This study sought to develop a practical method of predicting likelihood of prolonged response to treatment with serial doses of oral ketamine for chronic SI. Using $\mathrm{BN}$ methodology, we evaluated a combination of demographic variables and pre-treatment clinical measures to predict likelihood of prolonged therapeutic ketamine response at the end of the post-treatment follow-up period. Through use of multivariate scenarios, we demonstrated that employing demographic and clinical rating scale variables in a $\mathrm{BN}$ provides rich insights into networks of factors predicting likelihood of prolonged response to ketamine. The variables age, sex, 


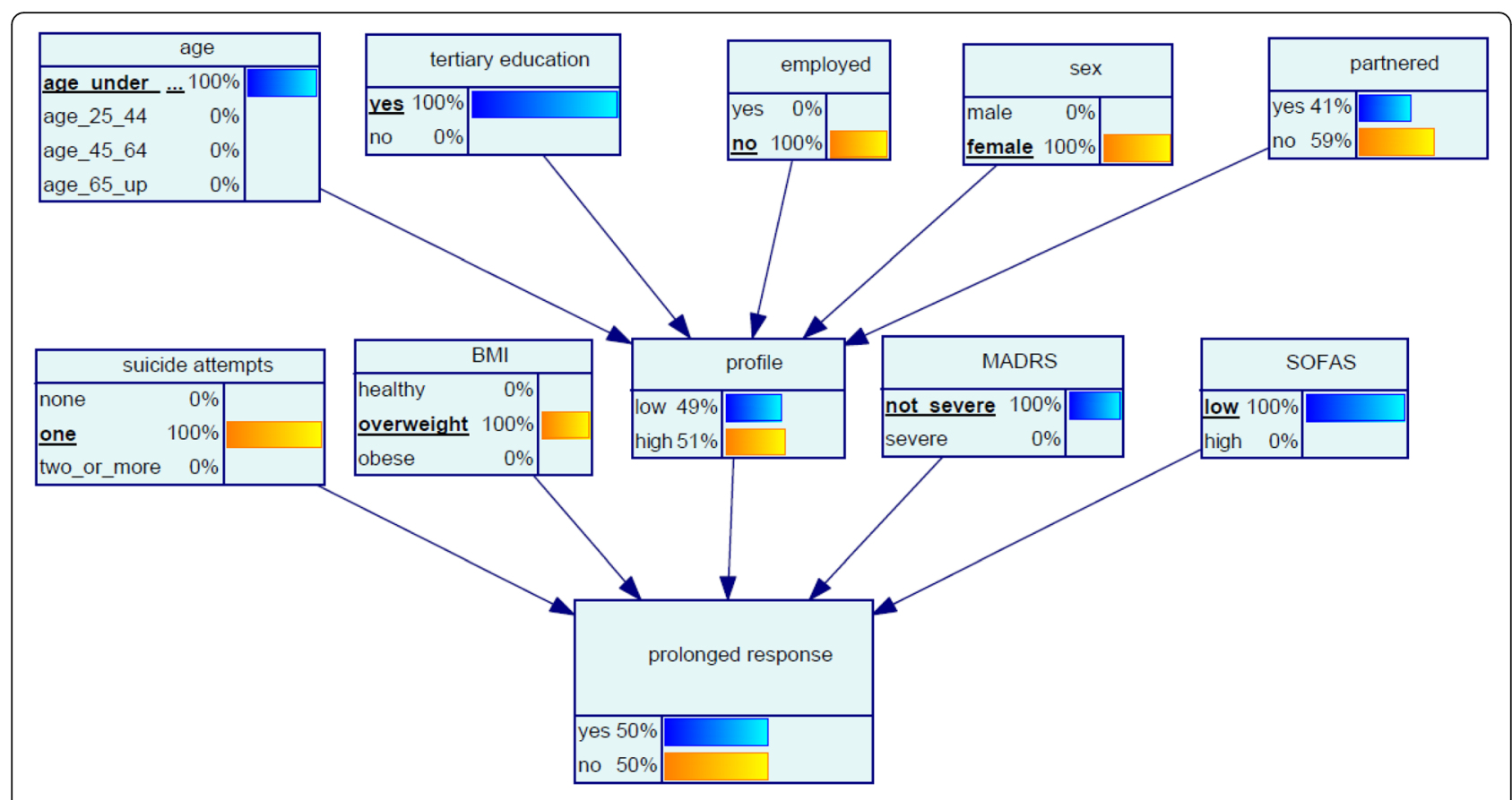

Fig. 3 Bayesian network (BN) for predicting chance of response to oral ketamine for Scenario 1 'Tiffany'

employment and partnered status, level of education, number of previous suicide attempts, BMI, depression symptoms and social and occupational functioning appeared to be key predictor variables for prolonged response to oral ketamine in the OKTOS trial.
Single variable modelling of the OKTOS data showed that ketamine treatment candidates were more likely to have a prolonged response to treatment if they were male, aged under 25 years, had no tertiary education, were not partnered, had no previous suicide attempts, a

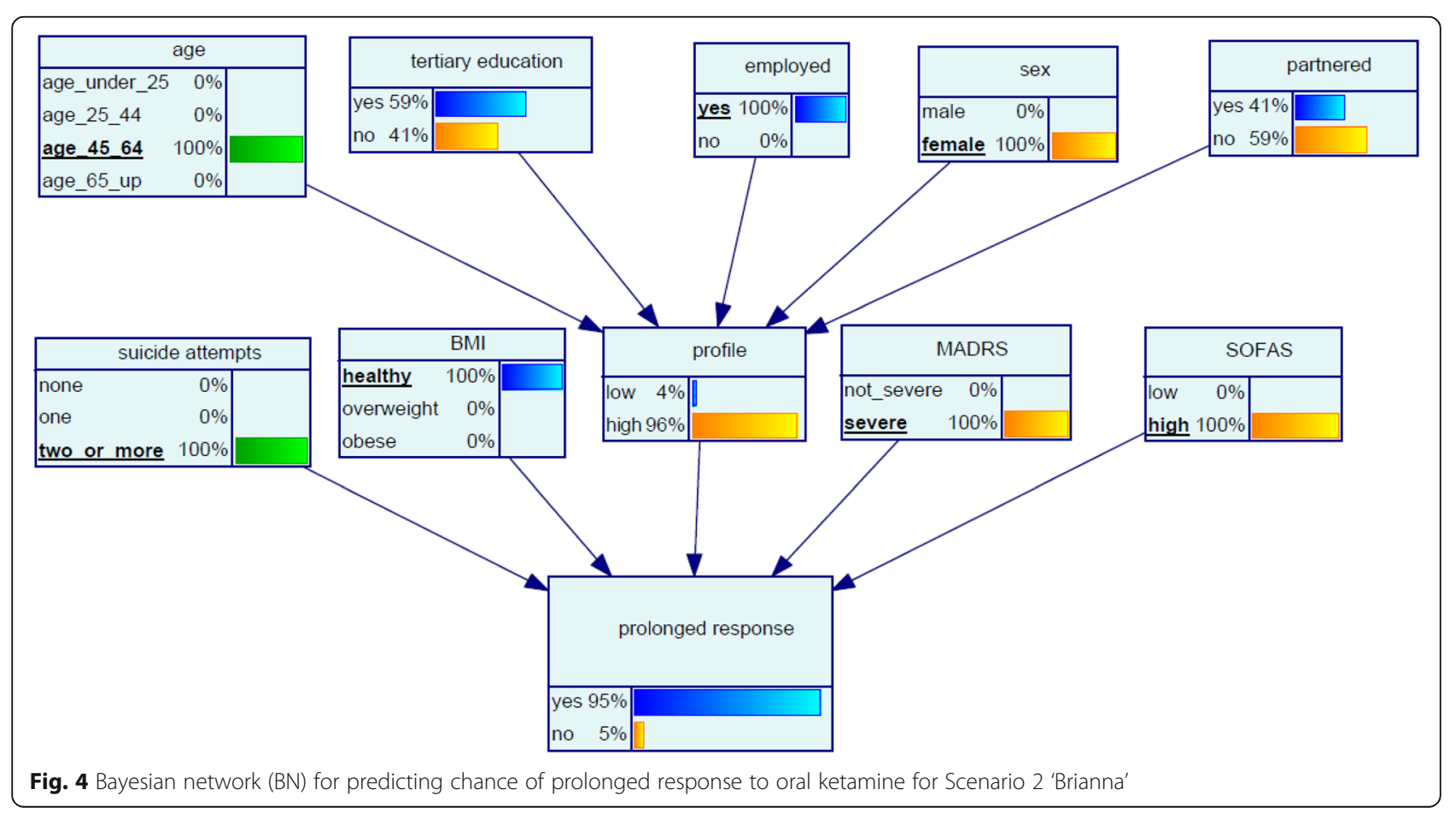




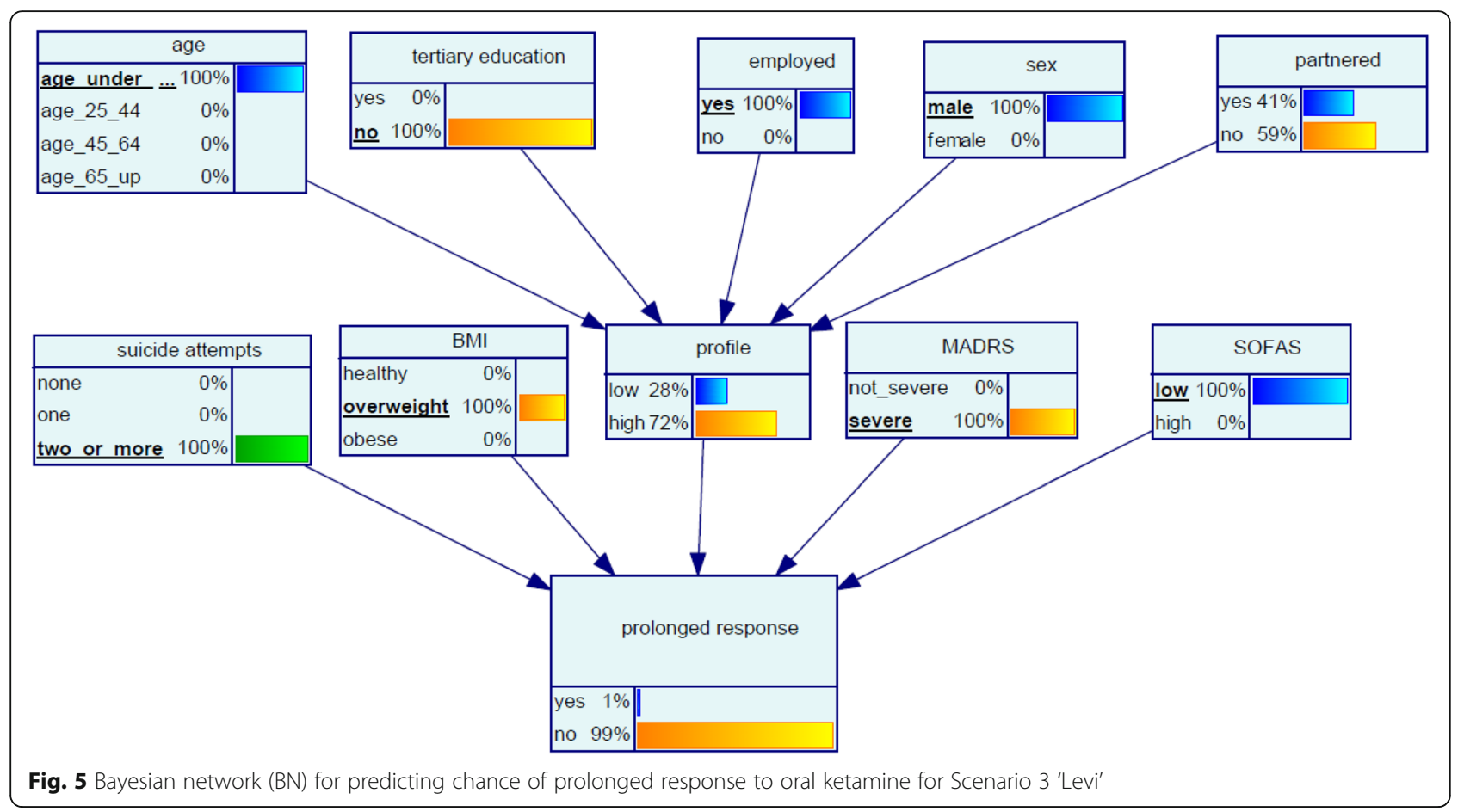

healthy BMI, a non-severe MADRS score and a high SOFAS score. The model did not predict high likelihood of prolonged response to oral ketamine in those who had had two or more previous suicide attempts; the single variable scenarios predicted improved chance of prolonged response for participants with no or one previous suicide attempt and decreased chance of response for participants with two or more previous attempts. However, suicide risk is not contingent solely on the history of previous attempts, but is influenced by a number of interacting factors, and our model endeavours to reflect some of the factors we believe mitigate and compound both the

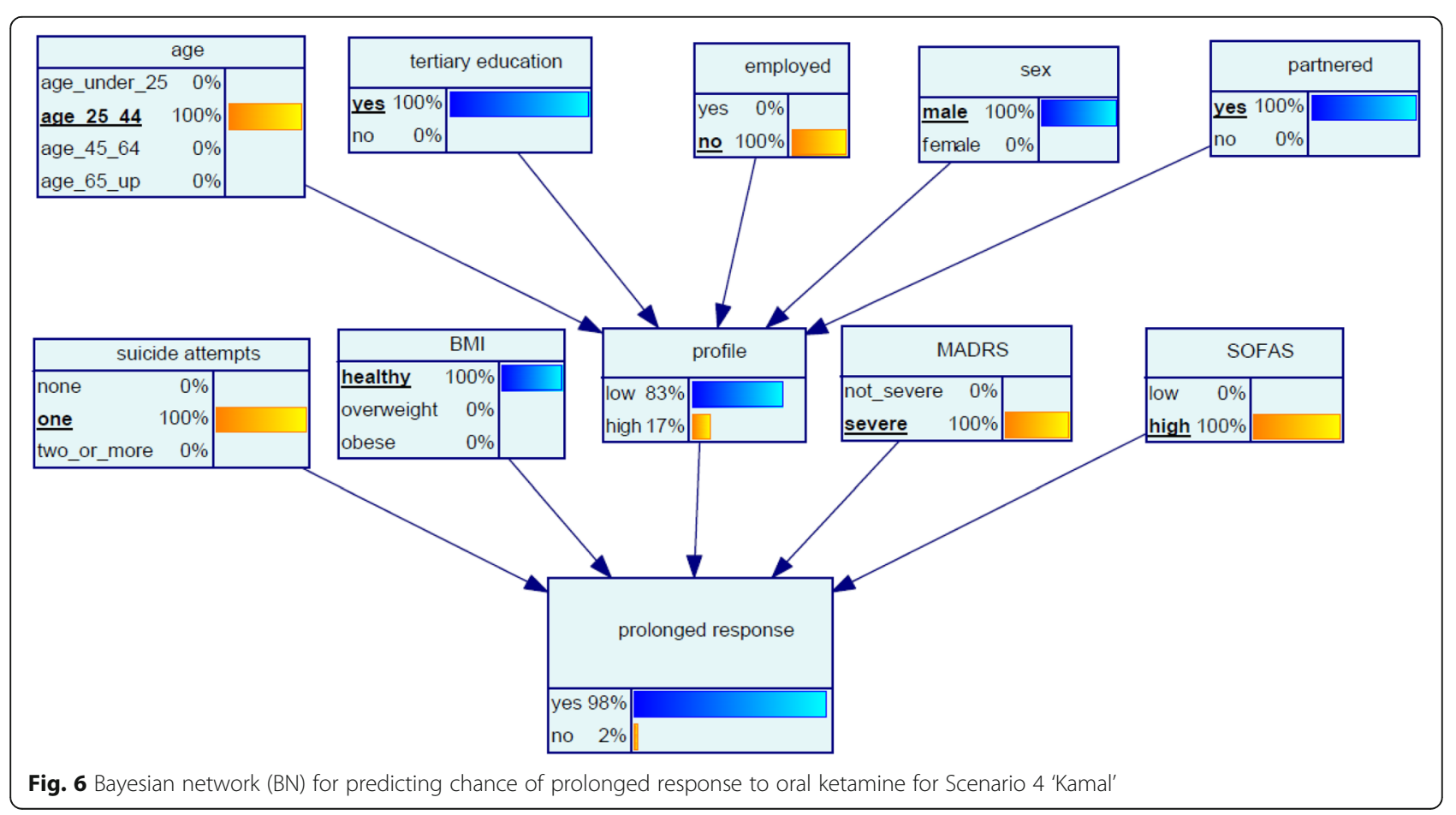


Table 6 Chance of response to ketamine as a result of evidence entry in single nodes - BN for predicting likelihood of prolonged response to oral ketamine. Baseline chance of prolonged response (no evidence entered) $=48 \%$, baseline chance of no prolonged response $=52 \%$

\begin{tabular}{|c|c|c|}
\hline $\begin{array}{l}\text { Single state } \\
\text { scenario }\end{array}$ & $\begin{array}{l}\text { \% chance of } \\
\text { prolonged response } \\
\left(\Delta_{\%}\right)^{\mathrm{a}}\end{array}$ & $\begin{array}{l}\% \text { chance of no } \\
\text { prolonged response } \\
\left(\Delta_{\%}\right)^{\mathrm{a}}\end{array}$ \\
\hline Age $<25$ years & $50(4)$ & $50(-4)$ \\
\hline Age $25-44$ years & $46(-4)$ & $54(4)$ \\
\hline Age 45-64 years & $50(4)$ & $50(-4)$ \\
\hline Age $\geq 65$ years & $47(-2)$ & $53(2)$ \\
\hline Sex male & $49(2)$ & $51(-2)$ \\
\hline Sex female & $48(0)$ & $52(0)$ \\
\hline Tertiary education & $47(-2)$ & $53(2)$ \\
\hline No tertiary education & $50(4)$ & $50(-4)$ \\
\hline Employed & $53(10)$ & $47(-10)$ \\
\hline Not employed & $46(-4)$ & $54(4)$ \\
\hline Partnered & $48(0)$ & $52(0)$ \\
\hline Not partnered & $49(2)$ & $51(-2)$ \\
\hline $\begin{array}{l}\text { No previous suicide } \\
\text { attempts }\end{array}$ & $57(19)$ & $43(-17)$ \\
\hline $\begin{array}{l}\text { One previous suicide } \\
\text { attempt }\end{array}$ & $50(4)$ & $50(-4)$ \\
\hline $\begin{array}{l}\text { Two or more } \\
\text { previous suicide } \\
\text { attempts }\end{array}$ & $44(-8)$ & $56(8)$ \\
\hline BMI healthy & $57(19)$ & $43(-17)$ \\
\hline BMI overweight & $34(-29)$ & $66(27)$ \\
\hline BMl obese & $49(2)$ & $51(-2)$ \\
\hline MADRS not severe & $59(23)$ & $41(-21)$ \\
\hline MADRS severe & $47(-2)$ & $53(2)$ \\
\hline SOFAS low & $37(-23)$ & $63(21)$ \\
\hline SOFAS high & $54(13)$ & $46(-12)$ \\
\hline
\end{tabular}

${ }^{\mathrm{a}} \Delta \%=\frac{P_{\text {evidence }}-P_{\text {baseline }}}{P_{\text {baseline }}} \times 100 \%$

risk, and response to the treatment. The relationship between the number of previous attempts and suicide risk warrants further investigation in future studies.

In exploring evidence introduction in single nodes further, we demonstrated that regardless of model response to evidence introduction in a single node, the same evidence in a multivariate scenario could increase or decrease likelihood of response, contingent on the combination of evidence in other nodes. This is an elegant illustration of the efficiency of the $\mathrm{BN}$ framework in modelling the mutual distribution of all states in all nodes in the network, considering node dependencies and any new evidence introduced to the network simultaneously. In practical terms, this representation of the joint probability distribution of the network demonstrates the utility of the BN in twenty-first century clinical decision support, where the volume of available data exceeds not only the capabilities of traditional analytical approaches, but also of human cognition.

An important finding that emerged was the target variable prolonged response was most sensitive to $B M I$, of all variables in the model (Table 5). Closer examination of model behaviour with respect to BMI inputs without evidence introduced in other nodes, revealed that a BMI in the healthy or obese range increased the chance of an individual demonstrating a prolonged therapeutic response to ketamine by 19 and $2 \%$, respectively (Table 6). However, the model indicated that a BMI in the overweight range decreased an individuals' chance of responding by $29 \%$ and increased their chance of no prolonged response by $27 \%$. Our results for both healthy and overweight BMI are inconsistent with a previous study by Niciu et al. (2014) [17], showing that a higher BMI was associated with greater response to IV ketamine; although the endpoint in that study was antidepressant response, as opposed to an endpoint of reduction in SI, as was the case in our study. Niciu et al. (2014) observed that the patients receiving the highest ketamine dose (in $\mathrm{mg}$ ) had greater improvements in their Hamilton Depression Rating Scale scores, suggesting that the association between BMI and acute antidepressant response might be a secondary effect of a relatively higher administered dose of ketamine. No significant association was found in OKTOS between higher doses of ketamine and greater improvements in either the BSS or the MADRS. Based on results of a subsequent study, the same researchers [50] suggested that systemic metabolic abnormalities might predict positive response to ketamine or at least have an indirect role in its therapeutic effects. These results were upheld in a study by Dale, Bryant [51], who concluded that BMI was not a predictor of response to ketamine, and outcome in antidepressant therapy was influenced by the presence of metabolic syndrome rather than obesity itself.

In artificial intelligence and Bayesian statistics, the principle of Occam's Razor is often used to simplify models, where the simplest solution is often the best one [52]. Development of this model was an iterative process, with varying permutations of variables, guided by the domain knowledge of mental health clinicians. However, parsimony is a primary goal in BN design, where the simplest structure should be used to describe the system under consideration [53]. Variables such as medication class (antidepressants, antipsychotics, mood stabilisers), the DASS21 (Anxiety), DASS21 (Stress) and DASS21 (Depression) subscales, and a dichotomous indicator for persistent pain were originally included in the model, however while these variables were surmised 
to be clinically relevant, they reduced the sensitivity of the network and were able to be excluded without forfeiting model accuracy.

According to the National Institutes of Health, precision medicine is an emerging approach for disease treatment and prevention "that takes into account individual variability in genes, environment, and lifestyle for each person" [54]. Precision medicine approaches allow doctors and researchers to predict more accurately which treatment and prevention strategies for a disease will work in which groups of people. The decision to use ketamine to combat chronic suicidal ideation is currently made by the clinician in collaboration with the patient. Systematic, evidence-based identification of pretreatment predictors of response to ketamine in chronically suicidal patients may streamline such decision making for clinicians, by empirically establishing the phenotype most likely to benefit from ketamine. The ability of $\mathrm{BN}$ to present and evaluate multiple paradigms is particularly appealing in understanding complex systems and they have the capacity to augment clinician judgement as probabilistic decision support systems in psychiatry and medicine.

\section{Limitations}

This study yielded a proof of concept $\mathrm{BN}$ for predicting ketamine response in chronic SI and has the following methodological limitations. First, the findings cannot be extrapolated to other populations without external validation on data sets other than the one used to develop the model, including utilisation in populations with acute SI. Second, the sample size which the $\mathrm{BN}$ was based upon was relatively small $(n=32)$, although technically, there is no minimum sample size for $\mathrm{BN}$ [55]; they have been shown to have good predictive accuracy with small sample sizes [55, 56], and Bayesian methods are often selected over frequentist methods to better accommodate reduced sample sizes [57]. However, these findings should be treated with some caution and future studies with larger sample sizes that replicate these analyses are warranted. Third, the data used in the model were from a secondary source, and some of the variables used to predict ketamine response in the literature (e.g., family history of alcohol use disorder, indicators of cognitive functioning) were not available for inclusion in the model. Nevertheless, the model created using OKTOS variables appears to provide accurate predictions. Fourth, the definition of therapeutic response used included $\geq 50 \%$ improvement in the pre-treatment BSS. This cut-off value was arbitrarily selected to define response, however the extent to which this threshold accurately reflects therapeutic changes in
SI is unknown. Lastly, the short post-ketamine follow-up period (4 weeks) was a limitation of the OKTOS trial, particularly as short follow-up for treatment efficacy is particularly unreliable for chronic conditions.

\section{Further research}

$\mathrm{BN}$ are an iterative modelling tool, and here we present a first iteration of a model which can potentially be developed with further data and wider consultation, to form a component in a desktop decision support system for clinicians. In this study, model inputs are pre-treatment measures - further model development could incorporate clinical ratings gathered during the treatment phase. Future iterations of the $\mathrm{BN}$ described here could also include tolerability and safety measures, including dissociative phenomena, cystitis and urinary incontinence; and other variables such as pre-treatment biochemistry (e.g., brain-derived neurotrophic factor), neurochemistry (e.g., glutamine/glutamate ratio), neuroimaging (e.g., anterior cingulate cortex activity), and cognitive functioning (i.e., processing speed). In other variations of the model, discretisation of clinical rating scales could be undertaken using expert elicitation with mental health clinicians. Finally, given the efficacy of oral ketamine over a period of 6 weeks, future studies should examine the longer-term effects including the efficacy of ketamine treatment over longer periods of time, including designs with less frequent dosing. The $\mathrm{BN}$ model developed here could undergo evaluation in subsequent clinical trials of ketamine, comparing model-predicted and actual response rates.

\section{Conclusion}

Ketamine appears to be a promising treatment for people with chronic SI, however further investigation to determine clinical utility on an individual basis is necessary. As we have shown, use of standard demographic data and commonly used clinical rating scales in a $\mathrm{BN}$ model can provide an objective synthesis of factors impacting likelihood of prolonged response to ketamine in individuals with chronic SI, supporting clinical decision making. Significantly, obtaining BMI, sociodemographic information and history of suicide attempts are all part of psychiatric history taking, and the clinical rating scales used in this model are frequently used to monitor individuals' clinical status during treatment. Finding simple, feasible predictors of therapeutic response to treatment is an important step towards improving the care of patients with chronic SI, in a context of suicide prevention. 


\section{Appendix}

Table 7 Thresholds and definitions for node states - Bayesian network for prediction of prolonged oral ketamine response

\begin{tabular}{|c|c|c|}
\hline Variable & Definitions and thresholds for states & $\begin{array}{l}\text { Discretisation method/ } \\
\text { source }\end{array}$ \\
\hline \multirow[t]{4}{*}{ Age } & age_under_25 $=<25$ years & determined by study authors \\
\hline & age_25_44 $=25 \leq$ years $<45$ & \\
\hline & age_45_64 $=45 \leq$ years $<65$ & \\
\hline & age_65_up $=\geq 65$ years & \\
\hline \multirow[t]{2}{*}{ Sex } & male & determined by study authors \\
\hline & female & \\
\hline \multirow[t]{2}{*}{ Tertiary education } & yes $=$ tertiary education & determined by study authors \\
\hline & no $=$ no tertiary education & \\
\hline \multirow[t]{2}{*}{ Employed } & yes $=$ employed; full time, part time or casual & determined by study authors \\
\hline & no $=$ unemployed or not in labour force & \\
\hline \multirow[t]{2}{*}{ Partnered } & yes $=$ married $/$ de facto & determined by study authors \\
\hline & no $=$ never married, widowed, divorced, separated & \\
\hline \multirow[t]{3}{*}{ Suicide attempts } & none $=$ no previous suicide attempt & determined by study authors \\
\hline & one $=$ one previous suicide attempt & \\
\hline & two_or_more $=\geq$ two previous suicide attempts & \\
\hline \multirow[t]{4}{*}{ BMI } & underweight $=<18.5$ & {$[58]$} \\
\hline & healthy $=18.5-24.9$ & \\
\hline & overweight $=25-29.9$ & \\
\hline & obese $=\geq 30$ & \\
\hline Profile & low, high; latent variable (unobserved, parameterised during automated learning) & not applicable; latent variable \\
\hline \multirow[t]{2}{*}{ MADRS } & not_severe $=\leq 34$ & [59] \\
\hline & severe $=>34$ & \\
\hline \multirow[t]{2}{*}{ SOFAS } & low $=<55$ & uniform widths \\
\hline & high $=\geq 55$ & \\
\hline $\begin{array}{l}\text { Prolonged } \\
\text { response }\end{array}$ & $\begin{array}{l}\text { yes }=(i) \geqslant 50 \% \text { improvement from pre-treatment BSS at the end of the post-treatment follow-up } \\
\text { phase, or } \\
\text { (ii) BSS score } \leq 6 \text { at the end of the post-treatment follow-up phase } \\
\text { no }=\text { no improvement as defined for 'yes' }\end{array}$ & determined by study authors \\
\hline
\end{tabular}

\section{Abbreviations}

AUC: Area under the curve; BMI: Body mass index; BN: Bayesian network; BSS: Beck Scale for Suicide Ideation; DASS21: Depression, Anxiety and Stress Scale (21 items); IV: Intravenous; MADRS: Montgomery-Asberg Depression Rating Scale; OKTOS: Oral Ketamine Trial on Suicidality; ROC: Receiver operating characteristic; SD: Standard deviation; SI: Suicidal ideation; SOFAS: Social and Occupational Functioning Assessment Scale

\section{Acknowledgements}

We thank the OKTOS participants for their contribution to this research.

\section{Authors' contributions}

$J \mathrm{~L}$ and $\mathrm{DH}$ procured funding for the research, $J \mathrm{~L}, \mathrm{AC}$ and $\mathrm{DH}$ designed and implemented the trial, $A C, M D$ and MJ provided clinical care of participants, $\mathrm{MD}, \mathrm{MJ}, \mathrm{CG}, \mathrm{CY}$ and GF gathered data, PS constructed the data pipeline, DB performed the data analyses and numerical simulations and drafted the manuscript, GS provided critical feedback on the manuscript. All authors contributed to both the manuscript and to model development and refinement. The author(s) read and approved the final manuscript.

\section{Funding}

This study was funded by a grant from the Australian Commonwealth Government's 'Prioritizing Mental Health Initiative' (2018-2019). The funders had no role in the design of the study; in the collection, analyses, or interpretation of data; in the writing of the manuscript, or in the decision to publish the results.

\section{Availability of data and materials}

The datasets generated and/or analysed during the current study are not publicly available for reasons of participant confidentiality but are available from the corresponding author on reasonable request.

\section{Ethics approval and consent to participate}

The trial was approved by the Bellberry Human Research Ethics Committee (\# 2017-12-982) and approval ratified by the University of the Sunshine Coast Human Research Ethics Committee (\# A181101). Informed, written consent was obtained from individual participants.

\section{Consent for publication}

Not applicable. 


\section{Competing interests}

The authors declare that they have no competing interests.

Received: 11 May 2020 Accepted: 19 October 2020 Published online: 28 October 2020

\section{References}

1. World Health Organisation. Preventing suicide: A global imperative. Luxembourg: World Health Organisation; 2014.

2. Australian Bureau of Statistics. Causes of Death, Australia, 2018-3303.0 2018 [updated 25/09/2019. Available from: https://www.abs.gov.au/ausstats/abs@. $\mathrm{nsf} / \mathrm{mf} / 3303.0$.

3. American Psychiatric Association. Diagnostic and statistical manual of mental disorders. 5th ed. Washington, DC: American Psychiatric Association; 2013

4. Machado-Vieira R, Baumann J, Wheeler-Castillo C, Latov D, Henter ID, Salvadore $\mathrm{G}$, et al. The timing of antidepressant effects: a comparison of diverse pharmacological and somatic treatments. Pharmaceuticals. 2010;3(1): 19-41.

5. Guzzetta F, Tondo L, Centorrino F, Baldessarini RJ. Lithium treatment reduces suicide risk in recurrent major depressive disorder. J Clin Psychiatry. 2007;68(3):380-3.

6. Meltzer HY, Alphs L, Green Al, Altamura AC, Anand R, Bertoldi A, et al. Clozapine treatment for suicidality in schizophrenia: International Suicide Prevention Trial (InterSePT). Arch Gen Psychiatry. 2003;60(1):82-91.

7. Liang CS, Chung $\mathrm{CH}$, Ho PS, Tsai CK, Chien WC. Superior anti-suicidal effects of electroconvulsive therapy in unipolar disorder and bipolar depression. Bipolar Disord. 2018;20(6):539-46.

8. Wasserman D, Rihmer Z, Rujescu D, Sarchiapone M, Sokolowski M, Titelman $D$, et al. The European Psychiatric Association (EPA) guidance on suicide treatment and prevention. Eur Psychiatry. 2012;27(2):129-41.

9. Berton O, Nestler EJ. New approaches to antidepressant drug discovery: beyond monoamines. Nat Rev Neurosci. 2006;7(2):137-51.

10. Rong C, Park C, Rosenblat JD, Subramaniapillai M, Zuckerman H, Fus D, et al. Predictors of response to ketamine in treatment resistant major depressive disorder and bipolar disorder. Int J Environ Res Public Health. 2018;15(4):771.

11. Berman RM, Cappiello A, Anand A, Oren DA, Heninger GR, Charney DS, et al. Antidepressant effects of ketamine in depressed patients. Biol Psychiatry. 2000;47(4):351-4.

12. Murrough JW, Perez AM, Pillemer S, Stern J, Parides MK, Aan Het Rot M, et al. Rapid and longer-term antidepressant effects of repeated ketamine infusions in treatment-resistant major depression. Biol Psychiatry. 2013;74(4): 250-6.

13. Wilkinson ST, Ballard ED, Bloch MH, Mathew SJ, Murrough JW, Feder A, et al. The effect of a single dose of intravenous ketamine on suicidal ideation: a systematic review and individual participant data meta-analysis. Am J Psychiatr. 2018;175(2):150-8.

14. Zhou Y, Liu W, Zheng W, Wang C, Zhan Y, Lan X, et al. Predictors of response to repeated ketamine infusions in depression with suicidal ideation: an ROC curve analysis. J Affect Disord. 2020;264:263-71.

15. Ballard ED, Yarrington JS, Farmer CA, Richards E, Machado-Vieira R, Kadriu B, et al. Characterizing the course of suicidal ideation response to ketamine. J Affect Disord. 2018;241:86-93.

16. Phelps LE, Brutsche N, Moral JR, Luckenbaugh DA, Manji HK, Zarate CA Jr. Family history of alcohol dependence and initial antidepressant response to an N-methyl-D-aspartate antagonist. Biol Psychiatry. 2009;65(2):181-4.

17. Niciu MJ, Luckenbaugh DA, lonescu DF, Guevara S, Machado-Vieira R, Richards EM, et al. Clinical predictors of ketamine response in treatmentresistant major depression. J Clin Psychiatry. 2014:75(5):e417-e23.

18. Rashidian H, Rosenblat JD, McIntyre RS, Mansur RB. Leptin, obesity, and response to ketamine. Prog Neuro-Psychopharmacol Biol Psychiatry. 2020; 98:1-4.

19. Del Sant LC, Magalhães E, Lucchese AC, Alves HNP, Sarin LM, Del Porto JA, et al. Clinical predictors of antidepressant response to ketamine in unipolar treatment-resistant depression. Eur Psychiatry. 2017;41:S525-S6.

20. Ionescu DF, Luckenbaugh DA, Niciu MJ, Richards EM, Slonena EE, Vande Voort $J$, et al. Effect of baseline anxious depression on initial and sustained antidepressant response to ketamine. J Clin Psychiatry. 2014;75(9):e932-e8.

21. Duncan WC Jr, Selter J, Brutsche N, Sarasso S, Zarate CA Jr. Baseline delta sleep ratio predicts acute ketamine mood response in major depressive disorder. J Affect Disord. 2013;145(1):115-9.
22. Alexander LM, Escalera J, Ai L, Andreotti C, Febre K, Mangone A, et al. Data descriptor: an open resource for transdiagnostic research in pediatric mental health and learning disorders. Sci Data. 2017:4:1-26.

23. Iniesta R, Stahl D, McGuffin P. Machine learning, statistical learning and the future of biological research in psychiatry. Psychol Med. 2016;46(12):245565.

24. Lucas PJ, Gaag LC, Abu-Hanna A. Bayesian networks in biomedicine and health-care. Artif Intell Med. 2004;30:201-14.

25. Jensen FV, Nielsen TD. Bayesian networks and decision graphs. New York: Springer; 2007.

26. Pearl J. Probabilistic reasoning in intelligent systems: networks of plausible inference. Morgan and Kaufman: San Mateo; 1988.

27. Zhang Z, Hamagami F, Wang L, Nesselroade JR, Grimm KJ. Bayesian analysis of longitudinal data using growth curve models. Int J Behav Dev. 2007;31(4): 374-83.

28. Van De Schoot R, Broere JJ, Perryck KH, Zondervan-Zwijnenburg M, Van Loey NE. Analyzing small data sets using Bayesian estimation: the case of posttraumatic stress symptoms following mechanical ventilation in burn survivors. Eur J Psychotraumatol. 2015;6:1-13.

29. Pearl J. Causality. Cambridge: Cambridge University Press; 2000.

30. Bilek G, Karaman F. An investigation into the relationship among psychiatric, demographic and socio-economic variables with Bayesian network modeling. Entropy. 2018;20(3):1-15.

31. Cleophas TJ, Zwinderman AH. Bayesian-network for efficacy analysis. In: Cleophas TJ, Zwinderman AH, editors. Efficacy analysis in clinical trials an update: efficacy analysis in an era of machine learning. Cham: Springer International Publishing; 2019. p. 75-85.

32. Bielza C, Larrañaga P. Bayesian networks in neuroscience: a survey. Front Comput Neurosci. 2014:8:131.

33. Katalinic N, Lai R, Somogyi A, Mitchell PB, Glue P, Loo CK. Ketamine as a new treatment for depression: a review of its efficacy and adverse effects. Aust N Z J Psychiatry. 2013:47(8):710-27.

34. Dundee JW, Fee JPH, Moore J, Mcllroy PDA, Wilson DB. Changes in serum enzyme levels following ketamine infusions. Anaesthesia. 1980;35(1):12-6.

35. aan het Rot M, Collins KA, Murrough JW, Perez AM, Reich DL, Charney DS, et al. Safety and efficacy of repeated-dose intravenous ketamine for treatment-resistant depression. Biol Psychiatry. 2010;67(2):139-45.

36. Zarate CA Jr, Brutsche NE, Ibrahim L, Franco-Chaves J, Diazgranados N, Cravchik A, et al. Replication of ketamine's antidepressant efficacy in bipolar depression: a randomized controlled add-on trial. Biol Psychiatry. 2012; 71(11):939-46.

37. Petteri Sokero T, Melartin TK, Rytsälä HJ, Leskelä US, Lestelä-Mielonen PS, Isometsä ET. Suicidal ideation and attempts among psychiatric patients with major depressive disorder. J Clin Psychiatry. 2003;64(9):1094-100.

38. Jones E, Oliphant E, Peterson P. SciPy: Open source scientific tools for Python 2001 [Available from: http://www.scipy.org].

39. American Psychiatric Association. Diagnostic and statistical manual of mental disorders. 4th ed. Washington, DC: American Psychiatric Association; 1994.

40. Hay P, Katsikitis M, Begg J, Da Costa J, Blumenfeld N. A two-year follow-up study and prospective evaluation of the DSM-IV axis V. Psychiatr Serv. 2003; 54(7):1028-30.

41. Seo H-J, Jung Y-E, Jeong S, Kim J-B, Lee M-S, Kim J-M, et al. Persistence and resolution of suicidal ideation during treatment of depression in patients with significant suicidality at the beginning of treatment: the CRESCEND study. J Affect Disord. 2014;155:208-15.

42. Beck AT, Kovacs M, Weissman A. Assessment of suicidal intention: the scale for suicide ideation. J Consult Clin Psychol. 1979;47(2):343-52

43. Horon R, McManus T, Schmollinger J, Barr T, Jimenez M. A study of the use and interpretation of standardized suicide risk assessment: measures within a psychiatrically hospitalized correctional population. Suicide Life Threat Behav. 2013:43(1):17-38

44. Williams JBW, Kobak KA. Development and reliability of a structured interview quide for the Montgomery-Åsberg depression rating scale (SIGM A). Br J Psychiatry. 2008;192(1):52-8

45. Montgomery SA, Åsberg M. A new depression scale designed to be sensitive to change. Br J Psychiatry. 1979;134(4):382-9.

46. Dempster AP, Laird NM, Rubin DB. Maximum likelihood from incomplete data via the EM algorithm. J R Stat Soc Ser B Methodol. 1977;39(1):1-38.

47. Lauritzen SL. The EM algorithm for graphical association models with missing data. Comput Stat Data Anal. 1995;19(2):191-201. 
48. Stone M. Cross-validatory choice and assessment of statistical predictions. J R Stat Soc. 1974;36(2):111-47.

49. Kjaerulff U, van der Gaag LC. Making sensitivity analysis computationally efficient. In: Sixteenth conference on uncertainty in artificial intelligence 2000. California: Morgan Kaufmann Publishers Inc.; 2000.

50. Machado-Vieira R, Gold PW, Luckenbaugh DA, Ballard ED, Richards EM, Henter ID, et al. The role of adipokines in the rapid antidepressant effects of ketamine. Mol Psychiatry. 2017;22(1):127-33.

51. Dale RM, Bryant KA, Thompson NR. Metabolic syndrome rather than body mass index is associated with treatment rresponse to ketamine infusions. J Clin Psychopharmacol. 2020;40(1):75-9.

52. Pothos EM. Occam and Bayes in predicting category intuitiveness. Artif Intell Rev. 2007;28(3):257-74.

53. Pollino C, Henderson C. Bayesian networks: a guide for their application in natural resource management and policy. Canberra: Integrated Catchment Assessment and Management Centre, Fenner School of Environment and Society, Australian National University; 2010

54. National Institutes of Health. Precision Medicine United States 2020 [Available from: https://ghr.nlm.nih.gov/].

55. Uusitalo L. Advantages and challenges of Bayesian networks in environmental modelling. Ecol Model. 2007;203:312-8.

56. Kontkanen P, Myllmäki P, Silander T, Tirri H. Comparing predictive inference methods for discrete domains. In: Proceedings of the sixth international workshop on artificial intelligence and statistics. New Jersey: AT\&T Labs; 1997. p. 311-8.

57. McNeish D. On using Bayesian methods to address small sample problems. Struct Equ Model. 2016;23(5):750-73.

58. World Health Organization (WHO). Obesity: preventing and managing the global epidemic. Report of a WHO consultation. Geneva: WHO; 2000.

59. Herrmann N, Black SE, Lawrence J, Szekely C, Szalai JP. The Sunnybrook stroke study a prospective study of depressive symptoms and functional outcome. Stroke. 1998;29(3):618-24.

\section{Publisher's Note}

Springer Nature remains neutral with regard to jurisdictional claims in published maps and institutional affiliations.

Ready to submit your research? Choose BMC and benefit from:

- fast, convenient online submission

- thorough peer review by experienced researchers in your field

- rapid publication on acceptance

- support for research data, including large and complex data types

- gold Open Access which fosters wider collaboration and increased citations

- maximum visibility for your research: over $100 \mathrm{M}$ website views per year

At $\mathrm{BMC}$, research is always in progress.

Learn more biomedcentral.com/submissions 